\title{
Responding To The Concerns Of Student Cultural Groups: Redesigning Spaces For Cultural Centers
}

Anise Mazone McDowell, University of Minnesota - Twin Cities, USA Jeanne L. Higbee, University of Minnesota - Twin Cities, USA

\begin{abstract}
This paper describes the engagement of a student committee in redesigning an entire floor of a university union to accommodate student cultural centers and provide space in a fair and equitable manner. The reorganization focused on the process as well as the task of allocating space, with an emphasis on the opportunity to foster the development of student leadership skills. Theories guiding the process included Chickering's seven vectors of college student development, the campus ecology model, the Social Change Model of Leadership, and universal design.
\end{abstract}

Keywords: Student Cultural Centers; College Unions; Social Change Model of Leadership; Universal Design

\section{INTRODUCTION: STATEMENT OF THE PROBLEM}

(n Spring 2010, the University of Minnesota, Twin Cities was challenged by the threat of a lawsuit related to the provision of space for student cultural centers. Two students questioned the allocation of semi-permanent space on the second floor of Coffman Memorial Union to some student groups and not others. Among its many other uses of space (e.g., lounges, dining facilities, meeting rooms, bowling alley, movie theater, staff and student offices, Great Hall for special events with large attendance), Coffman hosts 50 selfidentified cultural groups, but as of 2010 provided only 9 with dedicated, semi-permanent space for cultural centers: (a) Al-Madinah Cultural Center, (b) American Indian Student Cultural Center, (c) Asian-American Student Union, (d) Black Student Union, (e) Disabled Student Cultural Center, (f) La Raza Student Cultural Center, (g) Queer Student Cultural Center, (h) Women's Student Activist Collective, and (i) Minnesota International Student Association. These groups that had assigned space might be considered "umbrella" organizations, without necessarily being representative of the many cultures supposedly covered by the umbrella. The 9 cultural centers occupied $68 \%$ of the space in question, while the other 41 cultural groups at times had the opportunity to share spaces on the second floor, but never had assigned spaces of their own. On the second floor there was also the provision of space for two student government organizations - the Minnesota Student Association and the Graduate and Professional Student Association - as well as Commuter Connection. Meanwhile, at any given time there were more than 700 registered student groups with varying missions and memberships that paid student services fees and did not have the same opportunity to use the second floor space. The University of Minnesota Undergraduate Board of Governors (BOG) was charged by the Vice Provost for Student Affairs to determine how to serve more student cultural groups in the existing Coffman Union second floor space and to understand the rationale for providing semipermanent space to only nine student groups. The University of Minnesota was one of the first universities in the country to be challenged in this way, so it was important for the institution to prepare to address this issue in a democratic manner that included student involvement and could serve as a model process for other institutions. The University also hoped to avoid any formal legal action.

The purpose of this paper is to inform postsecondary administrators and policy makers about how student leadership development was considered in what otherwise could have been a mere redistribution of space by University officials. Specifically, the paper addresses the application of theory, including the Social Change Model of Leadership (SCM; Astin \& Astin, 1996), in a multicultural context in which students were given the 
responsibility to determine a fair and equitable reallocation of the space available. Successful application of SCM can prevent acrimonious and divisive disputes among those defending the principles and practices of multiculturalism and social justice. The paper also discusses the implementation of universal design to ensure inclusion.

\section{THE ROLE OF CULTURAL CENTERS}

The roles of cultural centers are similar in nature across centers; they serve as a home-away-from-home and are considered safe spaces. Yet they also serve unique purposes for different cultures. Certain cultural centers were born out of protests in the 1960s. "The cultural center was to be the place where attitudes, values, knowledge, and skills could be compared, debated, and shared" (Patton, 2006, p. 628). Native American cultural centers are important for their students because they provide a place where students can practice their traditions, such as drumming and smudging. Muslim cultural centers are a place where students, faculty, and staff may go to pray and build community. This particular cultural community includes people from all over the world, with religion being a common denominator. Similarly, in Latino cultural centers both language and religion bring students together. On many campuses the Queer Student Cultural Center was formed as a safe space for gay, lesbian, bisexual, and transgender students.

Patton (2010) asserted that the physical structure and location of a cultural center at a predominantly White institution (PWI) has an effect on its ability to serve students and provide an inclusive environment. When cultural centers have a central location they can attract and serve more students. The University of Minnesota, Twin Cities' provision of space for student cultural centers on the second floor of Coffman Memorial Union reflects its commitment to making the centers visible and accessible. Coffman is located on the University's East Bank Campus between the Mississippi River and Washington Avenue - a main thoroughfare for the campus - with easy access to buses and the new light rail. It also exemplifies the notion of home-away-from-home. Porter Butts (1928), who is considered the father of the college union movement, coined the term living room to express the function of college unions. Butts served as the first director of the Memorial Union at the University of Wisconsin-Madison, which was built during the same era as the Coffman Memorial Union. Thus, the notion of the college or university union as a welcoming space in which students can relax, engage in social interaction, and feel welcomed as they would in their own homes extends back to the early years of the "college union idea" (Butts et al., 2012). Situating student cultural centers within this context is consistent with the role of the centers and contributed to the decision that student leaders representing the different cultural centers be involved in designing their own "living rooms."

\section{THEORETICAL FRAMEWORKS}

The theoretical foundations for this project included Chickering's (1969; Chickering \& Reisser, 1993) seven vectors of college student development, the campus ecology model (Banning, 1978; Banning \& Kaiser, 1974), universal design (UD; The Center for Universal Design, 1997), and SCM. While SCM was used to guide student involvement in the project, the other three theories were also influential in the participatory planning process and in the completion of the architectural phases of the project.

\section{Chickering's Seven Vectors of College Student Development}

Chickering (1969; Chickering \& Reisser, 1993) emphasized the importance of developing interpersonal competence and recognizing interdependence as a reality of everyday life. His seven vectors of college student development include achieving competence, managing emotions, becoming autonomous, establishing identity, freeing interpersonal relationships, clarifying purpose, and developing integrity. Decades ago Chickering's theory was used as the foundation of a study on the development of leadership skills among students serving on union boards (Higbee, 1981).

For students to be effective members of the Second Floor Advisory Committee (SFAC), which served as the decision-making body for the project, they had to understand themselves first and be able to accept and trust others in order to realize the goals of the committee. Chickering used the term vector rather than stage to indicate that growth does not always involve a linear progression. Students sometimes have to reconsider how they perceive 
themselves and others as they engage in new relationships and gain new perspectives. They also must learn to stand up for their beliefs in the face of controversy and resistance. Chickering's conceptualization of integrity focuses on congruence between values and actions. Involvement in the SFAC provided a challenging context for growth for student participants. Chickering's work served as a reminder to staff facilitating the process to consider where students were in their individual development and how their evolution through Chickering's seven vectors might influence their behavior at any given time.

\section{Campus Ecology Model}

The campus ecology model (Banning, 1978; Banning \& Kaiser, 1974) also guided this project. The model assumes that not only does the college environment have an impact on students, but that students also have an impact on the institution and its environs. This model addresses this transactional relationship. Banning (1978) proposed that the model could be useful in designing learning spaces. More than 2 decades later, Strange and Banning (2001) developed four goals for the design of learning spaces: inclusion, safety, involvement, and community building. According to Evans, Forney, Guido, Patton, and Renn (2010), Strange and Banning proposed:

that these goals are enacted through physical, human aggregate, organizational, and constructed components of campus milieu. .. . Strange and Banning thus attended to the natural and human-built environments of campus geography and architecture, peer and other group interactions, structural aspects of the organization (such as administration, policy, and campus culture), and the ways individuals perceive, or construct, their environments. (pp. 170-171).

Thus, this theory seemed to provide a very appropriate model for the redesign of the Coffman Union's second floor.

Research supports that the decision-making process can promote learning and development (Kinzie \& Mulholland, 2008). University of Minnesota Student Unions and Activities (SUA) staff wanted to ensure that engaged participation in the redesign of the second floor would facilitate the development of student leadership and collaborative work skills. The goal of involvement within the campus ecology model provides a framework for participatory planning, which contributes to individual, group, and societal success (Smith, 1973). These values are also congruent with SCM's goals to enhance student learning and development and to foster individual development within a group collaborative process (Astin \& Astin, 1996).

When planning projects the participants often tend to focus on the outcome or goal, whereas in participatory planning the process itself is very important (Smith, 1973). "The fundamental legitimacy of participatory planning is based on plans and programs being endorsed, supported, and created by recipients" (Smith, 1973, p. 280), which is consistent with the campus ecology model's goal of building community. Clearly, acceptance of the outcome of the Coffman second floor redesign by various University constituent groups was vital, so student involvement as well as community building both within and between cultural groups were crucial in the redesign process.

Facilitators of the redesign project included student development practitioners and design professionals. These individuals, who perceived their role as "coaches," had to consider how students relate to space, environment, and people from their diverse perspectives. It was unlikely that there would be complete agreement about the reallocation and redesign of the Coffman Union second floor space for the cultural centers, so the goal was consensus. When students felt heard they were satisfied — even when the outcome was not in their favor.

\section{Social Change Model of Leadership}

In 1993 the University of California-Los Angeles' Higher Education Research Institute received a federal grant for development of a leadership program for undergraduates. The working ensemble had 15 members, led by Helen and Alexander Astin, and included other faculty, student affairs personnel, and graduate students (Astin \& Astin, 1996). The resulting model, SCM, is focused on building effective leaders and is widely used in student leadership programs at colleges and universities in the U.S. (Buschlen \& Dvorak, 2011; Dugan, 2006a, Dugan, 
2006b; Dugan \& Komives, 2007, 2010). It is a values-based model that promotes social change. The model's goals involve enhancing student learning and development within the context of serving as individual members of a group working collaboratively to accomplish a task. In addition, the model considers the relationship of these endeavors to the community or society as a whole. In the case of the Coffman Union second floor redesign, consideration of the University community as a whole was an important factor.

SCM is inclusive of all leaders, positional and non-positional. Leadership should be considered a process rather than a position or title (Astin \& Astin, 1996). SCM examines the seven Cs of leadership development: consciousness of self, congruence, commitment, common purpose, collaboration, controversy with civility, and citizenship. The hub of the seven Cs is change (Astin \& Astin, 2010). SCM also encourages students to reflect on their individual growth as members of the group and the development of the group as a whole and its role in facilitating social change. Although this paper focuses more on the application of SCM than on Chickering's seven vectors or the campus ecology model, it is impossible to differentiate among the influences of these theoretical perspectives that span more than 3 decades and have intertwined values and goals.

\section{Universal Design}

Universal design (UD; The Center for Universal Design, 1997) and its applications to teaching and learning were integral to the physical redesign aspect of this process. UD is an architectural concept that was first proposed by Ronald L. Mace as a proactive way to ensure inclusion following the passage of the Americans with Disabilities Act of 1990 (The Center for Universal Design, 1997). UD considers the needs of all potential users of a space in the design process. Features such as curb cuts and automatic door openers-initially designed to accommodate people with disabilities - are used by everyone. The guiding principles of UD include (a) "equitable use," (b) "flexibility in use," (c) "simple and intuitive use," (d) "perceptible information," (e) "tolerance for error," (f) "low physical effort," and (g) "size and space for approach and use" (The Center for Universal Design, 1997).

Universal instructional design (UID; Higbee \& Goff, 2008; Silver, Bourke, \& Strehorn, 1998) provided an additional theoretical framework to guide this project because of the need to ensure social inclusion and not just physical inclusion as reflected in the architectural model of UD. Just as an architect might consider all the potential users of a building, educators must consider all the potential participants in a course, program, or activity, and develop a plan that is respectful of differences in culture, language, religion, gender, orientation, age, ability, and so on. Recent work has applied UID more specifically to multicultural contexts (Higbee \& Goff, 2013; Higbee, Goff, \& Schultz, 2012; Higbee, Schultz, \& Goff, 2010).

\section{BACKGROUND}

The BOG did extensive research and benchmarked how 38 other universities that are similar to the University of Minnesota accommodate their student groups (University of Minnesota Student Unions \& Activities, 2013). The BOG then formed an ad hoc committee including affected groups, conducted a survey of all registered student organizations, did site visits to other universities, and held open meetings to seek further input from students. The BOG's results found that most other universities provide space for cultural centers, resource centers, and student government, and that funding was provided by student services fees, Coke grants, multicultural grants, student government grants, and fundraising. In their final recommendation that was forwarded to the Vice Provost, the BOG recommended that $68 \%$ of the space on the second floor be allocated to student cultural centers, $20 \%$ to common space for all student groups to use, $8 \%$ for undergraduate and graduate student government, and $4 \%$ to be made available for use by the student group that serves commuter students.

\section{FORMATION OF THE SECOND FLOOR ADVISORY COMMITTEE (SFAC)}

The student cultural centers were suspicious about the process and thought their voices were not being heard. They were concerned because they believed that they had no representation on the BOG and that the people bringing the initial complaint were a part of the board. They wanted to call for a halt to the process. They formed the Cultural Center Coalition to address their concerns. As a response to this group, in October 2011 the Second Floor Advisory Committee (SFAC) was formed. 
The SFAC was made up of student representatives from the BOG, the cultural centers, groups that would either be losing space or would not have space according to the BOG's plan for the division of the space, undergraduate and graduate student government, Commuter Connection, and the Student Emergency Loan Fund. Staff facilitators included co-advisors from the Office for Equity and Diversity, and one each from SUA and the Office of Student Affairs, for a total of 21 members and 6 alternates (University of Minnesota Student Unions \& Activities, 2013). The BOG representative served as the SFAC chair. Most SFAC members were student organization leaders, but their leadership skills did not necessarily align with the task upon which they were embarking.

\section{THE ROLE OF SCM IN THE COMMITTEE PROCESS}

SCM (Astin \& Astin, 2010) provided the structure for the work of the SFAC. The first time the SFAC met it reviewed the history of the second floor of Coffman Union. The BOG chair gave the members of the SFAC their charge. The group consisted of students representing different cultures and interests. Most of them appeared to know one another-some more than others. There was a bit of skepticism about the work upon which they were about to embark, but for the most part they were all eager to serve on the committee to ensure that all students' voices were heard and that the process was fully understood. They had worked long and hard to get to this decisionmaking table and they were excited about the possibilities of taking a leadership role on this committee. Students took time to introduce themselves and to talk about their cultural centers and the central missions for their organizations. At the end of the first meeting, the skeptics became the optimists.

The first order of business was to establish the ground rules for how the group was to work together-the norms for collaboration. The facilitators shared Garmston and Wellman's (2013) seven norms for collaboration: pausing, paraphrasing, probing, putting forth ideas, paying attention to self and others, presuming positive presuppositions, and pursuing a balance between advocacy and inquiry, all of which fit neatly within the framework of SCM.

Based on these norms, the members of the SFAC agreed on the following ground rules:

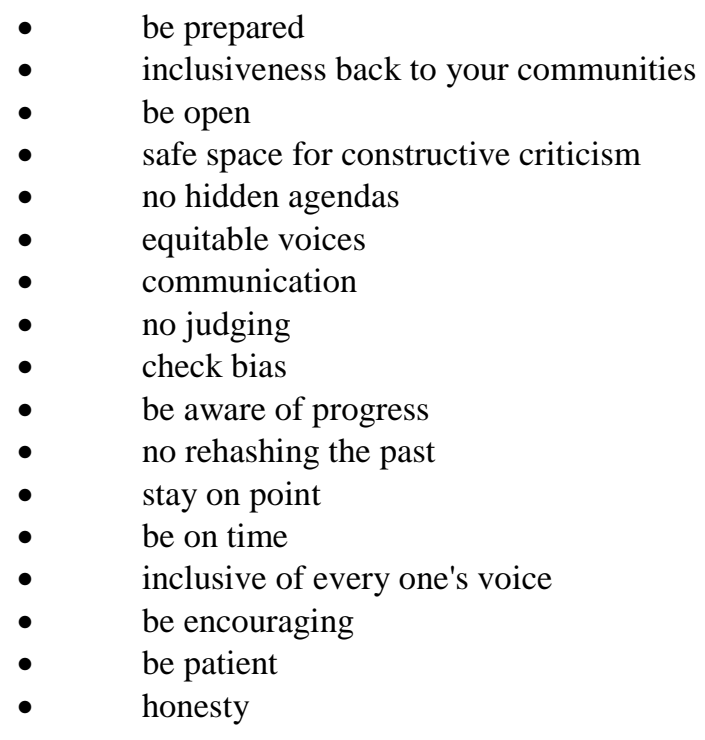

They continued to enforce these guidelines throughout the process.

\section{Goal Setting and Timeline}

It was important to lay out the details on the goal-setting and agenda-setting process. The first thing the SFAC asked was: "Where do we want to be when we are done?" The next step was to set up a timeline with some 
signposts to help inform the members of the group that they were moving in the right direction. The timeline had to include strict deadlines, but also needed to be flexible enough to leave room for unexpected challenges. In the beginning the unforeseen issues were related to individuals' self-awareness and their biases. Each time the SFAC met it had a clearly defined agenda and goals; the group needed to achieve its short-term goals in order to accomplish the long-term goal of redesigning the second floor to be ready by the beginning of the 2013-2014 academic year. It was also very important to post all the information about the committee and its timeline for everyone to access (University of Minnesota Student Unions \& Activities Board of Governors, 2013). Although relatively few people accessed it, the existence of a Web page dedicated to the status of the second floor redesign seemed to calm the fears of student cultural group members about this transformation. Transparency was vital to the process.

\section{Shift From Focus on the Individual to Concern for the Group and Larger Community}

In the beginning of the process some of the student representatives were concerned with how they were perceived by their peers and made statements like, "They're going to be mad at me if I say this . . .." It became important to direct their energy away from thinking about who was going to like or not like them, toward thinking about what is important to the student cultural centers and all students at the University. Meanwhile, between meetings it was not unusual for individual student representatives to meet with staff facilitators to discuss their concerns about not making the wrong decision on behalf of their respective student organizations.

After the students became knowledgeable about SCM, they started to examine their self-identities within the context of the SFAC, and after a couple of months were able to move on to working as productive group members. At that point they became concerned with questions about what aspects that are unique to their individual centers must remain intact throughout the renovation. Beyond considering how they could accommodate the cultural center they represented, they began to think about the redesign of the entire second floor and how to make it work for all students. The SFAC also had to think about who might be attending the University of Minnesota in the next 5,10 , or 15 years and using the space.

To establish a starting point, the SFAC began by reviewing the results of the BOG survey administered in 2010 to all of the more than 700 registered student groups on campus. The results provided information about what the student groups perceived they needed for the future and how they were currently using the second floor of Coffman. The SFAC decided to retool the survey to send out to all the officers of each student group to gather similar information in 2011, and devoted approximately 3 hours to discussing 12 survey questions because there was such robust conversation about each item. The committee continued to struggle with issues of trust; therefore, it took longer to accomplish each task because the committee had to slow down enough to ease fears. The students were still working on their individual development as members of the group as they progressed toward coalescing as a cohesive group so that they could envision a design that would accommodate all students and benefit the institution as a whole. From the very beginning the process reflected the three levels identified in SCM: the individual, the group, and the community.

\section{Facilitating Development of Student Leadership Skills}

SCM provided an appropriate theoretical framework to guide this process because the students became engaged in learning about how to lead effectively. As individuals they became more confident and worked on being intentional in building their leadership skills, they recognized the need to balance their own values and individual interests with those of others while working as part of this group.

Thus, the members of the SFAC came together around the common goal of creating a reorganization of Coffman Union's second floor that will strengthen community and will be inclusive of all students' needs. It was a long journey to get to the final recommendation to the BOG, but the committee was successful. Of the students who started with the SFAC, $90 \%$ stayed with the project to its completion. Everyone who started was there because of being passionate about the redesign issue. Initially some were passionate about being included in the decisionmaking process while others were passionate about halting the redesign. However, after establishing clear goals and assuring one another that they were all there for positive change, they had been able to move forward and function as a group focused on the best interests of the University community as a whole. 


\section{THE APPLICATION OF UNIVERSAL DESIGN IN DECISION MAKING}

The SFAC had to consider both the social and physical needs of the student cultural groups. Universal design was applied from the beginning of the process. All meetings were scheduled when convenient for the SFAC members and held in the Coffman Boardroom, which provided an accessible and welcoming environment; students were familiar and comfortable with the space. Given the early morning start time and the 3- to 4-hour length of the meetings, appropriate breaks and refreshments were provided.

Presentations and agendas were sent out in advance so that those using alternate formats to access these documents would have the opportunity to do so before the meeting. To ensure inclusion for an SFAC member who is blind, everyone adopted the practices of eliminating side conversations and saying their name before they spokepractices from which all can benefit. Presenters had to be very descriptive when they were explaining a slide or an object or a floor plan, leading to enhanced understanding for all members of the group.

Later in the process the weekly meetings moved to the designers' studio. Students worked in small groups using manipulatives to consider how the spacious second floor would be divided. Initially the focus was on the location of walls and doors; later the students were involved in the selection of furniture and its placement. Different types and heights of seating and work surfaces are provided, as well as flexibility in the arrangement of conversation groupings of lounge furniture.

Throughout this process the students and professional designers concentrated on ensuring that all spaces would be navigable and free of clutter. Everyone agreed that flexibility and visibility are vital. All entranceways have large double doors that can remain open wide when cultural center spaces are in use. Multiple methods are used to communicate layout, pathways, and individual cultural center and office entrances. For example, stripes in the carpeting assist in navigation and provide visual cues for cultural center entrances. Signage is provided in multiple formats, including Braille. All areas are well lit.

\section{CONSIDERING MULTICULTURAL PERSPECTIVES}

Multicultural perspectives and facets of social identity (e.g., race and ethnicity, disability, gender and gender identity, religion and spiritual beliefs, socioeconomic differences), and social justice considerations of power and privilege informed this entire project. Among SFAC members there were differences in sense of time and belief systems, and at times it was difficult to achieve a delicate balance that was respectful of all group members. For example, for purposes of time it was sometimes necessary to cut off speakers, when in their culture they would be allowed to speak until they are finished. Members of the committee who were not aware of this cultural nuance could be misinterpreted and their SFAC peers could be offended. SFAC members learned to communicate openly and honestly about what they meant or how they felt. This was a learning process for all. SFAC members' commitment to social justice was evident throughout the process. In the boardroom, where the weekly meetings were held, the playing field was leveled.

Later cultural beliefs and customs were also taken into consideration when assigning and designing the space for each cultural center. For example, additional soundproofing was installed for the American Indian Student Cultural Center to accommodate drumming. The new Al-Madinah Cultural Center is located in a space that provides privacy for prayer. The location of the Queer Student Cultural Center supports the anonymity of members of the community. There was a long discussion about the proximity and adjacency of centers for ease of collaboration among some cultural groups as well as separation of spaces for cultural groups that were worlds apart ideologically. The SFAC decided on an arrangement that was respectful of these beliefs and considered the emotional comfort of group members.

\section{CONCLUSION}

The second floor of Coffman Memorial Union now includes beautiful open lounge and study areas that serve all students as well as dedicated spaces for cultural groups and student government organizations. There are booths where students can sit and eat their lunches. There is a resource center that includes computer stations and 
provides equipment like a photocopier, paper cutter, and other tools available for use by all registered student organizations. There are also lockers available at three different height levels where students can store their belongings. There is no longer a sense that only a small minority benefits from the second floor space; everyone belongs. During the very first week after the opening of the redesigned space, it was clear that the students participating on the SFAC had been successful in meeting their design goals. The space was already heavily used by very diverse populations.

Only time will tell whether the inclusive new design of the second floor will remain functional for years to come. Efforts are already underway to evaluate the allocation of space and determine any adjustments that need to be made. The term used by the student members of the SFAC to describe their goals for the design was "everlasting." Although no space is going to last forever, it is hoped that the new design will remain flexible and allow for modifications that will not need to be precipitated by the threat of a lawsuit.

Achievement of the other goal of the project — the development of student leadership skills-may be less obvious to the casual observer and more difficult to measure. However, conversations with students involved in the SFAC illuminate their pride in taking on a daunting task, working through conflicts that at times were related to deeply entrenched attitudes and values, and collaborating in a planning process that was sensitive to the needs of diverse student groups. Students acknowledge their own development through this rich process, guided by SCM. It will be important for the Student Unions and Activities staff to engage in processes to formalize assessment of student growth to establish that the process can be as important as the outcome.

What is most noteworthy about the redesign of the second floor of Coffman Memorial Union is the nature of student involvement in the project. It would probably have been much easier and more time efficient for the SUA staff to steer the designers to produce several floor plan options and then put these choices to a vote by students, and perhaps also invite student feedback related to the selection of furniture types or makers. Students would have been given the illusion of participation in the redesign, but their involvement would have been superficial at best. Instead, the staff applied four theoretical approaches to guide a true participatory planning process that may have taken considerably more time, but was also likely to be far more productive in achieving goals and ensuring student satisfaction with the process and student use of the redesigned space. One purpose of this paper is to encourage other organizations to take a similar approach to engaging students in decision making regarding the spaces in which they learn.

\section{AUTHOR INFORMATION}

Anise Mazone McDowell earned a bachelor's degree in psychology from the University of Minnesota and was part of the first cohort in its MA program in Multicultural College Teaching and Learning from the Department of Postsecondary Teaching and Learning. Currently she works as the student engagement coordinator at the University's Student Unions \& Activities, where she co-advises the Second Floor Advisory Committee. This process and product won the University's 2013 Office for Equity \& Diversity Unit Award. She has extensive experience working to increase the aspirations of underrepresented students to seek higher education and educating parents on how they can understand and navigate the educational system to support their students. She is a skilled social justice and multicultural educator.

Jeanne L. Higbee has worked in higher education since 1974. She was on the Union Board as an undergraduate at Iowa State University in 1971-1972, and later worked as a program advisor at the Wisconsin Union in 1977-1980. Currently she serves as Professor and Director of Graduate Studies in the Department of Postsecondary Teaching and Learning at the University of Minnesota, Twin Cities, where she served as Anise's MA adviser. She is a 2007 American College Personnel Association (ACPA) Diamond Honoree and the recipient of the ACPA Voice of Inclusion Medallion (2005) and Disability Ally Award (2008). In 2011 she received the University of Minnesota's Horace T. Morse-University of Minnesota Alumni Association Award for Outstanding Contributions to Undergraduate Education. In 2013 she received the University's Access Achievement Award. E-mail: higbe002@umn.edu (Corresponding author) 


\section{REFERENCES}

1. Americans with Disabilities Act of 1990, 42 U.S.C.A. $§ 12101$ et seq. Retrieved from http://www.ada.gov/pubs/ada.htm

2. Astin, A. W., \& Astin, H. S. (2000). Leadership reconsidered: Engaging higher education in social change. Battle Creek, MI: W.K. Kellogg Foundation.

3. Astin, H. S., \& Astin, A. W. (1996). The social change model of leadership development guidebook. Version III. Los Angeles, CA: Board of Regents of the Univeristy of California, Higher Education Research Institute. Retreived from http://www.heri.ucla.edu/PDFs/pubs/ASocialChangeModelofLeadership Development.pdf

4. Banning, J. H. (Ed.). (1978). Campus ecology: A perspective for student affairs. Washington, DC: National Association of Student Personnel Administrators.

5. Banning, J. H., \& Kaiser, L. (1974). An ecological perspective and model for campus design. Personnel and Guidance Journal, 52, 370-375.

6. Buschlen, E., \& Dvorak, R. (2011). The social change model as pedagogy: Examining undergraduate leadership growth. Journal of Leadership Education, 10(2), 38-56.

7. $\quad$ Butts, P. (1928). The University furnishes its "living room." The Wisconsin Alumni Magazine, 29(5), 162183. Retrieved from http://digicoll.library.wisc.edu/cgi-bin/UW/UW-idx?type=turn\&entity= UW.v29i5.p0010\&id=UW.v29i5\&isize $=$ text

8. $\quad$ Butts, P., et al. (Eds.). (2012). The college union idea ( $2^{\text {nd }}$ ed.). Bloomington, IN: Association of College Unions International.

9. The Center for Universal Design. (1997). The principles of universal design, Version 2.0. Raleigh, NC: North Carolina State University. Retrieved from http://www.ncsu.edu/ncsu/design/cud/about_ud/ udprinciple

10. Chickering, A. W. (1969). Education and identity. San Francisco, CA: Jossey-Bass.

11. Chickering, A. W., \& Reisser, L. (1993). Education and identity (2 ${ }^{\text {nd }}$ ed.). San Francisco, CA: Jossey-Bass.

12. Dugan, J. P. (2006a). Explorations using the social change model: Leadership development among college men and women. Journal of College Student Development, 47(2), 217-225.

13. Dugan, J. P. (2006b). Involvement and leadership: A descriptive analysis of socially responsible leadership. Journal of College Student Development, 47(3), 335-343.

14. Dugan, J. P., \& Komives, S. R. (2007). Developing leadership capacity in college students: Findings from a national study. A Report from the Multi-Institutional Study of Leadership. College Park, MD: National Clearinghouse for Leadership Programs.

15. Dugan, J. P., \& Komives, S. R. (2010). Influences on college students'capacities for socially responsible leadership. Journal of College Student Development, 51(5), 525-549.

16. Evans, N. J., Forney, D. S., Guido, F. M., Patton, L. D., \& Renn, K. A. (2010). Student development in college: Theory, research, and practice (2nd ed.). San Francisco, CA: Jossey-Bass.

17. Garmston, R. J., \& Wellman, B. M. (2013). The adaptive school: A sourcebook for developing collaborative groups (2nd ed.). Lanham, MD: Rowman \& Littlefield.

18. Higbee, J. L. (1981). Student perceptions of their roles in the governance of college unions and the impact of participation on student development. (Doctoral dissertation). University of Wisconsin-Madison.

19. Higbee, J. L., \& Goff, E. (Eds.). (2008). Pedagogy and student services for institutional transformation: Implementing universal design in higher education. Minneapolis, MN: University of Minnesota, Center for Research on Developmental Education and Urban Literacy. Retrieved from http://www.cehd.umn.edu/passit/docs/PASS-IT-Book.pdf

20. Higbee, J. L., \& Goff, E. (2013). Widening participation through integrated multicultural instructional design. In K. Bridges, J. Shaw, \& I. Reid (Eds.), Inclusive higher education: An international perspective on access and the challenge of student diversity (pp. 41-55). Faringdon, Oxfordshire, UK: Libri.

21. Higbee, J. L., Goff, E., \& Schultz, J. L. (2012). Promoting retention through the implementation of integrated multicultural instructional design. Journal of College Student Retention, 14(3), 291-310.

22. Higbee, J. L., Schultz, J. L., \& Goff, E. (2010). The pedagogy of inclusion: Integrated multicultural instructional design. Journal of College Reading and Learning, 41(1), 49-66. 
23. Kinzie, J., \& Mulholland, S. (2008). Transforming physical spaces into inclusive multicultural learning environments. In S. Harper (Ed.), Creating inclusive campus environments (pp. 103-117). Washington, D.C.: National Association of Student Personnel Administrators.

24. Patton, L. D. (2006). The voice of reason: A qualitative examination of Black student perceptions of Black culture centers. Journal of College Student Development, 47(6), 628-646.

25. Patton, L. D. (Ed.). (2010). Culture centers in higher education: Perspectives on identity; theory; and practice. Sterling, VA: Stylus.

26. Silver, P., Bourke, A., \& Strehorn, K. C. (1998). Universal instructional design in higher education: An approach for inclusion. Equity and Excellence in Education, 31(2), 47-51.

27. Smith, R. W.(1973). A theoretical basis for participatory planning. Policy Sciences, 4, 274-295.

28. Strange, C. C., \& Banning, J. H. (2001). Educating by design: Creating campus learning environments that work. San Francisco, CA: Jossey-Bass.

29. University of Minnesota Student Unions \& Activities. (2013). Second floor project status. Minneapolis, MN: Author. Retrieved from http://sua.umn.edu/board/space/second floor-project-status/ 